DOI : 10.31357/fapsmph.2006.00621

Zinc and chromium in commonly used food items, intake by

Sri Lankan adults and their levels in serum

By

Balapanage Sumith Jayasinghe

M.Phil. 
Zinc and chromium in commonly used food items, intake by Sri Lankan adults and their levels in serum

\section{By}

\section{Balapanage Sumith Jayasinghe}

Thesis submitted to the University of Sri Jayewardenepura for the award of the Degree of Master of Philosophy in Biochemistry on 'Zinc and chromium in commonly used food items, intake by Sri Lankan adults and their levels in serum' on October 2006. 


\section{DECLARATION BY CANDIDATE}

The work described in this thesis was carried out by me under the supervision of Dr. (Mrs.) M.I.F.P. Jayawardene, (Department of Biochemistry, Faculty of Medical Sciences, University of Sri Jayewardenepura) and Dr. K.A.S. Pathiratne (Department of Chemistry, University of Kelaniya) and a report on this has not been submitted in whole or in part to any university or any other institution for another Degree/Diploma.

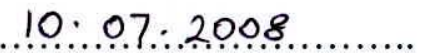

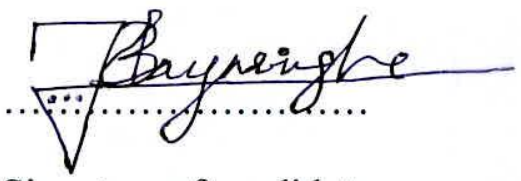

Date Signature of candidate 


\section{DECLARATION BY SUPERVISORS}

We certify that the above statement made by the candidate is true and that this thesis is suitable for submission to the University for the purpose of evaluation.

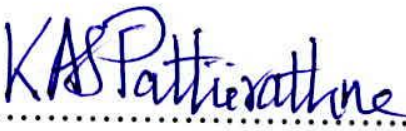

Dr. (Mrs.) M.I.F.P. Jayawardene

Dr. K.A.S. Pathiratne

Senior Lecturer

Head/ Senior Lecturer

Department of Biochemistry

Department of Chemistry

Faculty of Medical Sciences

University of Kelaniya

University of Sri Jayewardenepura

Kelaniya

Nugegoda

Sri Lanka

Sri Lanka 
I. LIST OF TABLES $x$

II. LIST OF FIGURES xiv

III. ABBREVIATIONS xvi

IV. ACKNOWLEDGEMENTS xviii

V. ABSTRACT $\quad x x$

1. INTRODUCTION 1

1.1 Background 1

1.2 Zinc and chromium 1

1.3 Food composition data 4

1.4 Justification of the study 5

1.5 Objectives of the study 7

1.5.1 Specific objectives of the study 7

2. LITERATURE REVIEW 8

2.1 Sri Lankan situation 8

2.1.1 Food supply 8

2.1.2 Nutritional status of adults 9

2.1.3 Dietary recommendations for Sri Lankan adults 9

$\begin{array}{ll}2.1 .4 \text { Food consumption } & 10\end{array}$

2.2 Zinc 13

2.2.1 Environmental levels and human exposure 14

2.2.2 Bioavailability of zinc $\quad 15$

2.2.3 Zinc homeostasis in humans $\quad 17$

$\begin{array}{lll}2.2 .4 & \text { Toxic effects on humans } & 17\end{array}$

$\begin{array}{ll}2.2 .5 \text { Zinc deficiency } & 18\end{array}$

2.4.5 Indices of zinc status 19

2.3 Chromium 20

2.3.1 Environmental levels and human exposure 21 
2.3.2 Daily requirements of chromium

2.3.3 Bioavailability of chromium 23

2.3.3.1 The glucose tolerance factor * 23

2.3.4 Chromium toxicity 24

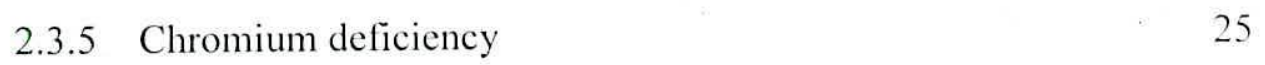

2.4 Sampling, sample preparation and analysis 26

2.4.1 Sampling 26

2.4.2 Sample preparation methods $\quad 27$

2.4.2.1 Wet decomposition 29

2.4.2.2 Dry ashing 31

2.4.3 Detection and measurement $\quad 32$

2.4.3.1 Detection of zinc in environmental samples 32

2.4.3.2 Detection of chromium in environmental samples 34

2.5 Quality control procedure 35

2.5.1 Recovery studies 36

2.5.2 Standard addition method 36

2.5.3 Certified reference materials $\quad 37$

$\begin{array}{lll}2.6 & \text { Food composition data } & 37\end{array}$

2.7 Dietary assessment in research involving human adults 38

2.7.1 Dietary assessment methods 39

2.7.1.1 Diet history 39

2.7.1.2 Food frequency questionnaire 40

2.7.1.3 Food record 41

2.7.1.4 24 hour recall $\quad 42$

2.8 Zinc and chromium status of serum 44

2.8.1 Determination of zinc in serum 44

2.8.2 Determination of chromium in serum 46

3. MATERIALS AND METHODS 51

$3.1 \quad$ Water, glassware and chemicals 51

3.2 Food samples 51

3.2.1 Sampling locations 51 
3.2.2 Sample size $\quad 52$

3.3 Sample preparation and preservation $\quad 52$

3.3.1 Sample preparation methods 53

3.3.1.1 Dry ashing 53

3.3.1.2 Wet digestion 54

3.3.1.2.i Kjeldahl method 54

3.3.1.2.ii Open digestion method $\quad 55$

3.4 Instrumentation $\quad 55$

3.4.1 Estimation of zinc in digested foods 55

3.4.1.1 Preparation of standard solutions $\quad 56$

3.4.1.2 Construction of calibration curve 56

3.4.1.3 Sample analysis $\quad 56$

3.4.1.4 Reporting the results 56

3.4.2 Estimation of chromium in digested foods 57

3.4.2.1 Preparation of standard solutions 59

3.4.2.2 Construction of calibration curve 59

3.4.2.3 Sample analysis 59

3.4.2.4 Reporting the results 60

3.4.2.5 Analytical characteristics $\quad 60$

3.5 Validation of the methods 60

3.5.1 Certified reference materials 61

3.5.2 Recovery studies 61

3.5.2.1 Recovery studies for zinc 61

3.5.2.2 Recovery studies for chromium 62

3.5.3 Standard addition method $\quad 62$

3.5.3.1 Standard addition method for zinc 62

3.5.3.2 Standard addition method for chromium 63

3.6 Determination of zinc and chromium levels in milk samples 63

3.6.1 Samples 63

3.6.2 Sample preparation 63

3.6.2.1 Determination of zinc and total chromium by wet digestion method 63 
3.6.2.2 Determination of total chromium by direct slurry method

3.6.2.3 Separation of hexavalent chromium in milk

3.6.2.3.i Apparatus

3.6.2.3.ii Procedure

3.6.3 Analytical procedure

3.6.3.1 Estimation of zinc in milk samples

3.6.3.2 Estimation of chromium in milk samples

3.6.4 Recovery studies 66

3.6.4.1 Recovery studies for zinc in milk 66

3.6.4.2 Recovery studies for total chromium in milk 67

3.6.4.2.i Wet digestion

\subsubsection{2.ii Direct slurry method}

3.6.4.3 Recovery method for hexavalent chromium in milk

3.7 Determination of zinc and chromium in water

3.7.2 Quantification of zinc in water

3.8.2.1. Accuracy of the method

3.7.2.1.i Standard addition method for zinc

3.7.3. Quantification of total and hexavalent chromium in water

3.7.3.2 Pre-concentration of hexavalent chromium

3.7.3.3 Pre-concentration of total chromium

3.7.3.4 Analytical conditions and validity of the method

3.7.3.5 Optimization of sample pre-treatment for total chromium

3.7.3.6 Accuracy of the method

3.7.2.6.i Recovery studies

3.7.2.6.ii Standard addition method for chromium

3.8.1 Twenty four hour recall method 
3.8.1.1 Sampling methodology

3.8.1.2 Ethical consideration 73

3.8.1.3 Equipment 73

3.8.1.4 Surveys 73

3.8.1.5 Anthropometrics characteristics 74

3.8.1.5.i Body weight 74

3.8.1.5.ii Height 74

3.8.1.5.iii Body mass index 75

3.8.1.6 Dietary intake 75

3.8.1.7 Calculation of percentage adequacy 75

3.8.1.8 Statistical analysis $\quad 75$

3.8.2 Market basket method 76

3.8.2.1 Food types $\quad 76$

$\begin{array}{ll}3.8 .2 .2 \text { Food preparation } & 77\end{array}$

3.8.2.3 Analytical procedure 78

3.8.2.4 Validation of the methods 78

3.9 Serum zinc and chromium levels in Sri Lankan adults $\quad 78$

$\begin{array}{lll}3.9 .1 \text { Subjects } & 78\end{array}$

3.9.2 Ethical clearance $\quad 78$

$\begin{array}{ll}3.9 .3 \text { Collection of blood samples } & 78\end{array}$

$\begin{array}{lll}3.9 .4 & \text { Statistical analysis } & 79\end{array}$

3.9.5 Determination of serum zinc levels by flame atomic absorption spectrometry $\quad 80$

3.9.5.1 Apparatus - Flame atomic absorption spectrometry 80

3.9.5.2 Procedure 80

3.9.5.3 Accuracy evaluation 81

3.9.5.3.i Standard addition method 81

3.9.6 Determination of serum chromium levels 81

3.9.6.1 Apparatus - electrothermal atomic absorption spectrometry 81

3.9.6.2 Analytical conditions 81

$\begin{array}{lll}3.9 .6 .3 & \text { Procedure } & 82\end{array}$ 
3.9.6.4. Accuracy evaluation

3.9.6.4.i Recovery studies

3.9.6.4.ii Standard addition method

4.1 Levels of zinc in foods $\quad 85$

4.1.1 Analysis of zinc using flame atomic absorption spectrometry 85

4.1.2 Comparison of performances of different digestion methods 85

4.1.3 Method validation 86

4.1.4 Calibration $\quad 88$

4.1.5 Zinc levels in foods $\quad 89$

4.1.5.1 General comments $\quad 89$

4.1.5.2 Cereals and cereal products 90

4.1.5.3 Pulses and legumes 91

4.1.5.4 Vegetables 92

4.1.5.4.i Leafy vegetables 92

4.1.5.4.ii Flowers and stems 93

4.1.5.4.iii Roots and tubers 95

4.1.5.5 Fruits 96

4.1.5.6 Meat, egg and fish 97

4.1.5.7 Milk and milk products 98

4.1.5.8 Fats and oils 99

$\begin{array}{ll}\text { 4.1.5.9 Other foods } & 100\end{array}$

$\begin{array}{ll}4.2 & \text { Levels of chromium in foods } \\ & 102\end{array}$

4.2.1 Estimation of chromium in digested foods 102

4.2.2 Comparison of different digestion methods 103

$\begin{array}{lll}\text { 4.2.3 Method validation } & 104\end{array}$

$\begin{array}{ll}4.2 .4 \text { Calibration } & 106\end{array}$

$\begin{array}{ll}\text { 4.2.5 Chromium levels in foods } & 107\end{array}$

4.2.5.1 General comments 107

$\begin{array}{ll}\text { 4.2.5.2 Cereals and cereal products } & 107\end{array}$

$\begin{array}{ll}\text { 4.2.5.3 Pulses and legumes } & 108\end{array}$ 
4.2.5.4 Vegetables 109

4.2.5.4.i Leafy vegetables 109

4.2.5.4.ii Flowers and stems 111

4.2.5.4.iii Roots and tubers 112

4.2.5.5 Fruits 113

4.2.5.6 Meat, egg and fish 114

4.2.5.7 Milk and milk products $\quad 115$

4.2.5.8 Fats and oils 116

4.2.5.9 Other foods 116

4.3 Quantification of total and hexavalent chromium in water using electrothermal atomic absorption spectrometry 118

4.3.1 Analytical conditions and validation of the method 118

4.3.2 Accuracy of the method 119

4.3.2.1 Total chromium 119

4.3.2.2 Hexavalent chromium 120

4.4. Estimation of total and hexavalent chromium in milk by electrothermal atomic absorption spectrometry $\quad 121$

4.4.1 Analytical conditions and validity of the method 121

4.4.2 Optimization of sample pre-treatment procedure 122

4.3.2.1 Total chromium 122

4.4.2.2 Hexavalent chromium 122

4.5 Dietary intake of Sri Lankan adults 123

4.5.1 Twenty four hour recall method 123

4.5.1.1 Anthropometric characteristics of the subjects $\quad 124$

4.5.1.1.i Height 124

4.5.1.1.ii Weight 124

4.5.1.1.iii Body mass index 126

4.5.1.2 Food habits and intake patterns $\quad 127$

4.5.1.3 Protein intake 128

4.5.1.3.i Relationship between the protein intake and age of the subjects $\quad 132$

4.5.1.4 Energy intake 
4.5.1.4.i Relationship between the energy intake and age of the subjects

4.5.1.4.ii Energy intake per $\mathrm{kg}$ of body weight 134

4.5.1.4.iii Percentage of energy from protein 135

4.5.1.5 Zinc intake

4.5.1.5.i Relationship between the zinc intake and age of the subjects

4.5.1.5.ii Relationship between energy intake and $\mathrm{Zn}$ intake

4.5.1.6 Chromium intake

4.5.1.6.i Relationship between chromium intake and age of the subjects

4.5.1.6.ii Relationship between energy intake and chromium intake

4.5.1.7 Average intake of energy, protein, zinc and chromium as a percentage of recommended levels

4.5.1.8. Food intake pattern of the subjects

4.5.2 Market basket method

4.6 Zinc and chromium levels in serum

4.6.1 Serum zinc

4.6.1.1 Relationship between the serum zinc level and age of the subjects

4.6.1.2 Relationship between energy intake and serum zinc level

4.6.1.3 Relationship between zinc intake and serum zinc level

4.6.2. Analysis of serum chromium by electrothermal atomic absorption spectrometry

4.6.2.1 The relationship between the serum chromium level and age of the subjects

4.6.2.2 Relationship between serum chromium level and energy intake 
4.6.2.3 Relationship between serum chromium level with chromium intake of the subject

5.

DISCUSSION

6.

CONCLUSIONS

207

REFERENCES

209

APPENDIX

249 


\section{List of Tables}

Table 2.1

Table 2.2

Table 2.3

Table 2.4

Table 2.5

Table 2.6

Table 3.1

Table 3.2

Table 4.1

Table 4.2

Table 4.3

Table 4.4

Table 4.5

Table 4.6

Table 4.7

Table 4.8

Table 4.9

Table 4.10

Table 4.11

Table 4.12
Nutritional status of adults

Dietary recommendations for Sri Lankan adults

Recommended food intakes (grams per day) to meet the recommended dietary allowances

Food consumption data on national level

Dietary factors affecting zinc bioavailability

Estimated safe and adequate daily dietary intake

for chromium

Optimized furnace temperature programme used for atomization of chromium from samples

Optimized furnace temperature programme used for

determination of chromium in serum

Levels of zinc found in certified reference materials using

different digestion methods

Accuracy and precision of the method compared with the value of certified reference materials

Recovery data for various food samples

Comparison of results for analysis zinc using direct calibration and standard addition methods

Content of zinc in selected Sri Lankan cereals and cereal products

Content of zinc in some selected Sri Lankan pulses and legumes

Content of zinc in selected Sri Lankan leafy vegetables

Content of zinc in selected Sri Lankan flowers and stems

Content of zinc in selected Sri Lankan roots and tubers

Content of zinc in several selected Sri Lankan fruits

Contents of zinc in selected Sri Lankan meat, egg and fish

Content of zinc in selected Sri Lankan varieties of milk and milk products 
Table 4.13 Content of zinc in selected Sri Lankan fats and oils

Table 4.14 Content of zinc in selected Sri Lankan spices

Table 4.15 Content of zinc in selected Sri Lankan beverages and sugar

Table 4.16

Levels of chromium found in certified reference materials using different digestion methods

Table 4.17 Accuracy and precision of the method against certified reference materials

Table 4.18

Recovery data for various food samples

Table 4.19 Comparison of results for analysis chromium using direct calibration and standard addition methods Content of chromium in selected Sri Lankan cereals and cereal products

Table 4.21 Content of chromium in selected Sri Lankan pulses and legumes

Table 4.22 Content of chromium in selected Sri Lankan leafy vegetables

Table 4.23 Content of chromium in selected Sri Lankan flowers and stems

Table 4.24 Content of chromium in selected Sri Lankan roots and tubers

Table 4.25

Content of chromium in selected Sri Lankan fruits

Table 4.26

Content of chromium in selected Sri Lankan meat, egg and fish

Table 4.27 Content of chromium in selected Sri Lankan varieties of milk and milk products

Content of chromium in selected Sri Lankan fats and oils Content of chromium in selected Sri Lankan beverages and sugar

Table 4.31 Recoveries of total and hexavalent chromium with direct method and column method Total chromium and hexavalent chromium contents in drinking water samples 
Table 4.33

Table 4.34

Table 4.35

Table 4.36

Table 4.37

Table 4.38(a)

Table 4.38(b)

Table 4.39

Table 4.40

Table 4.41

Table 4.42

Table 4.43

Table 4.44

Table 4.45

Table 4.46

Table 4.47

Table 4.48

Table 4.49

Table 4.50

Table 5.1

Table 5.2

Table 5.3
Results of the recovery studies for determination of total and hexavalent chromium

Daily food intake patterns of the Sri Lankan adults

Energy, protein, zinc and chromium intake of Sri Lankan men 129 Energy, protein, zinc and chromium intake of Sri Lankan women

Protein intake $\mathrm{g} / \mathrm{kg}$ body weight

Percentage protein intake per unit of body weight of

Sri Lankan adults

Energy intake of Sri Lankan adults

Daily food intake patterns of the Sri Lankan adults

Daily intakes of $\mathrm{Zn}$ and $\mathrm{Cr}$ in the Sri Lankan total diet contributions of major food groups to daily intakes

Percentage contribution from the main food groups to the total intake of zinc and chromium

market basket samples from four locations basket samples from four locations the method of addition

Mean serum zinc levels of Sri Lankan men and women and direct calibration methods

Reported zinc levels in milk in different countries

Total energy intake and percentage of energy from protein Mean body mass index and prevalence of overweightness in selected countries 
Table 5.4

Reported dietary intake levels of $\mathrm{Zn}$ and $\mathrm{Cr}$ in other countries 180

Table 5.5

Comparison of reported dietary intake and serum zinc levels

of different countries with those of present levels 


\section{List of Figures}

Figure 4.1

Figure 4.2

Figure 4.3

Figure 4.4

Figure 4.5

Figure 4.6

Figure 4.7

Figure 4.8

Figure 4.9

Figure 4.10

Figure 4.11

Figure 4.12

Figure 4.13

Figure 4.14

Figure 4.15

Figure 4.16
A calibration curve for the analysis of zinc using FAAS

A calibration curve for analysis of chromium using ETAAS

Weighted Pearson's correlation between the body mass index

and the age of the men and women in the group

Weighted Pearson's correlation between protein intake and age of the men and women in the group

Weighted Pearson's correlation between energy intake and age of the men and women in the group

Weighted Pearson's correlation between energy intake/kg

b.wt. and age of the men and women in the group

Weighted Pearson's correlation between percentage of energy

from protein and age of the men and women in the group

age of the men and women in the group

Weighted Pearson's correlation between energy intake and

zinc intake of the men and women in the group

Weighted Pearson's correlation between $\mathrm{Cr}$ intake and the

age of the men and women in the group

138

Weighted Pearson's correlation between energy intake

and $\mathrm{Cr}$ intake of the men and women in the group

Daily intakes of energy, protein and zinc as a percentage

of the Sri Lankan RDA and chromium as a percentage of

ESADDI (NRC, 1989)

Average daily intakes of foods by food group, in the Sri

Lankan total diet

Percentage contributions from major food groups to zinc intake

Percentage contributions from major food groups to chromium

Intake

Weighted Pearson's correlation between serum Zn level 
and age of the men and women in the group

Figure 4.17 Weighted Pearson's correlation between energy intake

and serum zinc level of the men and women in the group

Figure 4.18 Weighted Pearson's correlation between $\mathrm{Zn}$ intake and serum

$\mathrm{Zn}$ level of men and women in the group

Figure 4.19 Weighted Pearson's correlation between the age and the serum $\mathrm{Cr}$ level of the men and women in the group

Figure 4.20 Weighted Pearson's correlation between energy intake and serum $\mathrm{Cr}$ level of men and women in the group

Figure 4.21 Weighted Pearson's correlation between $\mathrm{Cr}$ intake and serum

$\mathrm{Cr}$ level of men and women in the group 


\section{ABBREVIATIONS}

\begin{tabular}{ll} 
24 HR & - 24 hour recall \\
AAS & - Atomic absorption spectrometry \\
AOAC & - Association of Official Analytical Chemists \\
APDC & - Ammonium pyrrolidine dithiocarbamate \\
ASV & - Anodic stripping voltammetry \\
BMI & - Body mass index \\
BMR & - Basal metabolic rate \\
BW & - Body weight \\
CAD & - Coronary artery disease \\
CMP & - Capacitively coupled microwave plasma \\
CRM & - Certified reference materials \\
CSV & - Cathodic stripping voltammetry \\
DCS & - Department of Census and Statistics of Sri Lanka \\
DH & - Diet history \\
DP-ASV & - Differential-pulse Anodic stripping voltammetry \\
EDTA & - Ethylene di-amine tetra acetic acid \\
EHC & - Environmental health criteria \\
ESADDI & - Estimated safe and adequate daily dietary intake \\
ETAAS & - Electrothermal atomic absorption spectrometry \\
FAAS & - Flame atomic absorption spectrometry \\
FAO & - Food and Agricultural Organization \\
FFQ & - Food frequency questionnaires \\
FI & - Flow injection \\
GTF & - Glucose tolerance factor \\
HDL & - High density lipids \\
IAEA & - International Atomic Energy Agency \\
ICDA & - International Chromium Development Association \\
ICP-AES & - Inductively coupled plasma atomic emission spectrometry \\
ICP-MS & - Inductively coupled plasma mass spectrometry \\
INCLEN & - International Clinical Epidemiological Network \\
IOS & - International Organization for Standardization \\
\hline A
\end{tabular}




$\begin{array}{ll}\text { LOD } & \text { - Limit of detection } \\ \text { LOL } & \text { - Level of linearity } \\ \text { MRI } & \text { - Medical Research Institute } \\ \text { NAA } & \text { - Neutron activation analysis } \\ \text { NHANES III } & \text { - The third national health and nutrition examination survey } \\ \text { NRC } & \text { - National Research Council } \\ \text { RDA } & \text { - Recommended dietary allowances } \\ \text { SD } & \text { - Standard deviation } \\ \text { SEM } & \text { - Standard error of mean } \\ \text { SF-ICP-MS } & \text { - Sector-field inductively coupled plasma mass spectrometry } \\ \text { US-EPA } & \text { - Environmental Protection Agency, United States } \\ \text { VAD } & \text { - Vitamin A deficiency } \\ \text { WHO } & \text { - World Health Organization } \\ \text { XRF } & \text { - X-ray fluorescence }\end{array}$




\section{ACKNOWLEDGEMENT}

I express my deepest gratitude to my supervisors Dr. (Mrs.) M.I.F.P. Jayawardene and Dr. K.A.S. Pathiratne for their guidance, help and encouragement given me throughout this study. And I address special thanks to Dr. K.A.S. Pathiratne for giving me the opportunity to learn and to be confident on atomic absorption spectrometric analysis and his endless patience in correcting my thesis and improving my writing.

I extend my warmest gratitude to Professor E.R. Jansz who was an endless source of help and advice during this period. I am grateful to Professor Nalini Wickramasinghe, Professor Hemantha Peiris, Dr. Sagarika Ekanayake and other academic staff of the Department of Biochemistry, Faculty of Medical Sciences, University of Sri Jayewardenepura for their advice and numerous supports in the achievement of this work. Also my sincere gratitude goes to the non academic staff members of the department for their numerous supports.

I extended my warmest gratitude to Professor W.D.W. Jayatilake, Department of Chemistry, Dr. Upul Subasinghe, Mr. Wijesinghe and other academic and non academic members of the Department of Forestry and Environmental Science, University of Sri Jayewardenepura for providing me with numerous support and very useful materials.

I would like to thank Professor Rohan Weerasooriya, Institute of Fundamental Studies, Kandy, for his valuable guidance at the initial stage of this study and directing me to the Dr. K.A.S. Pathiratne's lab. 
My sincere gratitude goes to my research colleagues, Indika, Channa, Chandika, Lakshmee, Inoka and non academic staff of the Department of Chemistry, University of Kelaniya, for their numerous supports.

I am happy to acknowledge my research colleagues Sumuduni, Keerthi, Chamani, Sampath, Shiromi, Chaminda, Samantha, Inoka, Sugandika, Darshika, Ishira and Nadee for their endless support and motivation. I am also thankful to my friends, Sisira Ediriweera, Pradeep Rajathewa, Ruwanthi Gunawardene and her family for the help given me during the preparation of this thesis.

Special thanks are due to my mother, brothers \& sisters and their families for their boundless faith and love extended to me in achieving my goals. Finally I would like to express my indebtedness to my wife for her sacrifice and understanding. Without her encouragement and understanding it would have been impossible for me to finish this work. 


\title{
Zinc and chromium in commonly used food items, intake by Sri Lankan adults
} and their levels in serum

\section{Balapanage Sumith Jayasinghe}

\begin{abstract}
Zinc and chromium are two essential trace elements required in modest amounts to maintain health and optimal physical function of humans. Trace elements either toxic or essential, reach the human body through foods, drinks, ambient air and other occupational and accidental exposures. There are no reported data on levels of these metals in foods, environmental samples, and dietary intake levels of the population with their serum levels in Sri Lanka. The aim of the present study is to determine $\mathrm{Zn}$ and $\mathrm{Cr}$ in commonly used food items and to determine the intake and the levels of $\mathrm{Zn}$ and $\mathrm{Cr}$ in serum of Sri Lankan adults and compare their intake levels with respect to serum levels of $\mathrm{Zn}$ and $\mathrm{Cr}$.
\end{abstract}

Individual food items (categorized into groups) were analysed for $\mathrm{Zn}$ and $\mathrm{Cr}$ using flame atomic absorption spectrometry (FAAS) and electrothermal atomic absorption spectrometry (ETAAS) respectively. Accuracy and validity of the results were examined by analyzing certified reference materials [IAEA-155, Whey powder and IAEA140/TM, Sea weeds (Fucus sp.)], which gave expected values.

Dietary energy, protein, $\mathrm{Zn}$ and $\mathrm{Cr}$ intake were measured by using twenty-four-hour recall method (24 HR) in a selected group of Sri Lankan adult men and women age 20 to 59 years. In order to compare the reported dietary intakes of $\mathrm{Zn}$ and $\mathrm{Cr}$, market baskets containing more than a hundred food items included in the average Sri Lankan diet were purchased from 4 locations: Colombo, Kandy, Dambulla and Balangoda. 
Freeze dried homogenates representative of each basket of food from each location were then dry ashed and analysed for $\mathrm{Zn}$ and $\mathrm{Cr}$ elements using FAAS and ETAAS respectively.

The 24 HR reported mean dietary $\mathrm{Zn}$ intakes of Sri Lankan adult men and women were $8.6 \pm 1.7 \mathrm{mg} /$ day and $7.2 \pm 1.3 \mathrm{mg} /$ day respectively. Market basket results reported the average $\mathrm{Zn}$ level to be $9.4 \pm 0.2 \mathrm{mg} /$ day. Based on the $24 \mathrm{HR}$, the mean dietary $\mathrm{Cr}$ intakes of Sri Lankan adult men and women were $65.3 \pm 32.3 \mu \mathrm{g} /$ day and $62.6 \pm 34.6$ $\mu \mathrm{g} /$ day respectively. Market basket results reported the average $\mathrm{Cr}$ level to be $70.0 \pm 1.0$ $\mu \mathrm{g} /$ day. These reported $\mathrm{Zn}$ and $\mathrm{Cr}$ intakes were comparable with several research studies conducted worldwide. The results of the dietary intake survey indicate that the dietary intake of $\mathrm{Zn}$ is lower than the recommended dietary allowance (RDA) of Sri Lanka and intake level is nearly $60 \%$ for men and $72 \%$ for women. In all the cases, the reported $\mathrm{Cr}$ intake levels were above the lower limit of the safe and adequate daily dietary intake levels of $50-200 \mu \mathrm{g} /$ day suggested by the National Research Council, USA (1989).

In estimation of the serum levels of $\mathrm{Zn}$ and $\mathrm{Cr}$, serum samples were diluted with a mixture of $1 \% \mathrm{HNO}_{3}$ and $2 \%$ Triton $\mathrm{X}-100$ and analysed for $\mathrm{Zn}$ and $\mathrm{Cr}$ using FAAS and ETAAS respectively. For the whole population mean serum $\mathrm{Zn}$ for men and women were $93.8 \pm 3.0 \mu \mathrm{g} / \mathrm{dl}$ and $91.4 \pm 3.2 \mu \mathrm{g} / \mathrm{dl}$ respectively. Reported mean serum $\mathrm{Cr}$ for men and women were $4.4 \pm 0.3 \mu \mathrm{g} / \mathrm{dm}^{3}$ and $3.9 \pm 0.2 \mu \mathrm{g} / \mathrm{dm}^{3}$ respectively. In this limited number of samples, serum $\mathrm{Zn}$ and $\mathrm{Cr}$ levels decreased with age. In order to decide the correlation between $\mathrm{Zn}$ and $\mathrm{Cr}$ intake of individuals with their respective values in serum, further extensive research including bioavailability studies are needed. 